\title{
Viruses of endophytic and pathogenic forest fungi
}

\author{
Abu Bakar Siddique ${ }^{1}$ \\ Received: 11 October 2019 / Accepted: 27 April 2020 / Published online: 9 May 2020 \\ (c) The Author(s) 2020
}

\begin{abstract}
Mycoviruses, just as the fungal endophytes they infect, are ubiquitous biological entities on Earth. Mycoviruses constitute a diverse group of viruses, and metagenomic approaches have-through recent discoveries of been mycoviruses—only recently began to provide evidence of this astonishing diversity. The current review presents (1) various mycoviruses which infect fungal endophytes and forest pathogens, (2) their presumed origins and interactions with fungi, plants and the environment, (3) high-throughput sequencing techniques that can be used to explore the horizontal gene transfer of mycoviruses, and (4) how the hypo- and hypervirulence induced by mycoviral infection is relevant to the biological control of pathogenic fungi.
\end{abstract}

Keywords Mycovirus $\cdot$ Fungal endophytes $\cdot$ High-throughput sequencing $\cdot$ Fungi $\cdot$ Mycobiome $\cdot$ Endophyte virus

\section{Fungal endophytes and mycoviruses}

Fungi that reside inside living organisms without causing visible symptoms during at least one part of their life cycle are generally known as endophytic fungi [1,2]. These fungi are hyperdiverse and ubiquitous, existing in all major habitats-marine, plant, animal, lichen, and soil [3-7]. Therefore, it is not surprising that endophytes perform various functions. For example, mycorrhizal fungi, endophytes, and lichens drive nutrient cycling and influence biomass production through a mutualistic relationship [8]. Leaf, litter and soil fungi include symbiotrophs, saprotrophs, or decomposing fungi which can degrade leaf and litter [7, 9-11]. In grass species, endophytes get shelter, nutrition, and transmission by host propagules; as a favor, endophytes increase host protection from herbivores and increase tolerance against different kind of stress factors, such as drought [12]. In contrast, tree endophytes are horizontally transmitted and predominantly non-systemic in that their life cycles are quite cryptic and they often exert a neutral influence on their host [13].

Edited by Seung-Kook Choi.

Abu Bakar Siddique

abu.ba.siddi@gmail.com

1 Department of Ecology and Environmental Sciences (EMG), Umeå University, Umeå, Sweden
Endophytes have a wide variety of functions-from mutualistic or symbiotic to pathogenic - that depend on host and/or environmental conditions [14]. For example, endophytes can help a plant become resistant to certain pathogens $[15,16]$, harmful fungi (e.g., Melamspora rust in poplar) and herbivorous insects $[17,18]$.

Viruses that multiply in fungi are generally known as mycoviruses [19]. The first mycovirus was discovered when the cause for mushroom die-back disease was investigated [20], after which the knowledge base concerning mycoviruses has expanded gradually. At present, hundreds of mycoviruses have been discovered [21], with most of the known species having a doubled-stranded RNA (dsRNA) genome, and a small share having either a single-stranded RNA (ssRNA) and single-stranded DNA (ssDNA) genome. A schematic representation of a dsRNA virus is provided in Fig. 1. According to ICTV (https://talk.ictvonline.org/), mycoviruses are classified into seven families, yet many species are not included in the existing classification system, which is based on genomic structure, virion structure, the amino acid sequence of the RNA-dependent RNA polymerase (RdRp), and the presence or absence of coat protein. The Totiviridae, Partitiviridae, Megabirnaviridae, Chrysoviridae, Quadriviridae and Reoviridae are most abundant mycovirus families [22-25]. Mycoviruses are not considered infectious per se (with a few exceptions), as they lack an extracellular route for infection and spread exclusively via spore production and hyphae conjugation. 


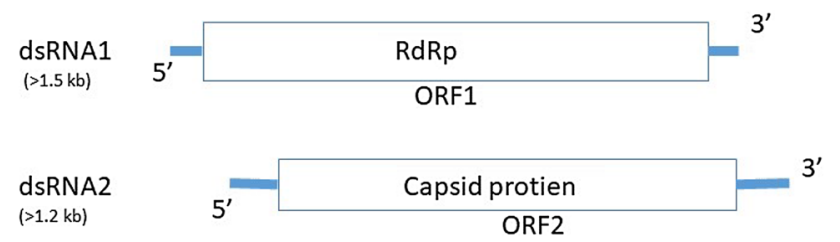

Fig. 1 Schematic representation of genome organization of a dsRNA virus. $R d R p$ RNA-dependent RNA polymerase, $O R F$ open reading frame

The estimated number of fungal endophyte species has constantly increased as environmental sampling and highthroughput sequencing (HTS) technologies have evolved and become cheaper for researchers. Recent estimates suggest that it is likely that between 1.5 and 10 million fungal endophyte species exist [26, 27], and scientists have stated that $30-80 \%$ of fungal species may be infected with mycoviruses [23, 25]. These estimates of the sheer number of fungal endophyte species suggests that recent discoveries of novel mycoviruses are just the tip of the iceberg, with most mycoviruses still undiscovered. During the last few years, most mycovirus research has focused on identifying the viruses which infect the pathogenic fungi of important crops, as these discoveries could be relevant to the biological control of harmful fungi. As a result, the mycoviruses which infect non-pathogenic fungi have largely been overlooked. Hence, as most endophytes remain undiscovered due to a presumed lack of pathogenicity, latent forest pathogens could be a great resource for novel mycovirus discovery.

\section{Origin of mycoviruses}

The origin of mycoviruses remains a debated topic, with two main hypotheses dominating the discussion. The first hypothesis for how mycoviruses originated is the ancient coevolution hypothesis, which suggests that viruses and fungi coevolved over time [28]. The second hypothesis proposes that mycoviruses evolved from plant viruses to occupy the niche of infecting plant-associated fungi [19, 25]. This theory cites previous evidence that certain mycoviruses have foreign structural units or domains which are assumed to be of eukaryotic or plant origin [29]. Mycovirus evolution is dominated by strong purifying selection; as such, low genome variability can be expected. Researchers are currently interested in using molecular biology methods to reveal how these structural units affect the host through either viral infection studies or simply expressing the element within fungal cells.

\section{Viruses of endophytes and forest fungi}

Viruses have been detected in all forms of fungi, from endophytes (e.g., Trichoderma harzianum) to obligate parasites (e.g., Puccinia striiformis) [30, 31]. Bao and Roossinck [32] provided an overview of the putative viruses of 52 distinct endophytes, revealing that almost all endophyte classes are assumed to have mycoviruses living in them (for a more detailed description refer to [32]). A large portion of the currently known mycoviruses infect grass endophytes, with research reporting that 53 different grass endophytes are infected by mycoviruses [33, 34]. More specifically, the dsRNA virus Epichloe festucae virus 1 (EfV1) was identified from the grass endophyte Epichloe festucae [32]. Tree endophytes can also serve as hosts for mycoviruses. For example, a mycovirus was detected in Colletotrichum gloeosporioides, an endophyte which harms cashew trees (Anacardium occidentale L.) by causing anthracnose [35]. Furthermore, viruses from the Endornaviridae family, which can infect plants, fungi and oomycetes, were found in root mycorrhizal Ceratobasidium fungi $[36,37]$. Ong et al. studied the fungal symbionts of Pterostylis sanguinea, a wild orchid from western Australia, and found 22 novel mycoviruses from the investigated fungi [37]. Moreover, mycoviruses not only infect filamentous, phytopathogenic fungi, but have also been reported in edible mushrooms, which demonstrates their commercial significance [38, 39]. Additionally, the parasitic fungi of mushrooms were found to contain mycoviruses [40].

Mycoviruses are widespread among certain forest fungi. For example, the fungus Gremmeniella abietina, which causes canker in coniferous trees across Europe and America, serves as a host for several mycoviruses. Phenotypic changes were frequently observed when the fungus was infected with multiple viruses. Characterizing these viruses, as well as understanding their evolutionary histories, could provide information about their route of transmission and interaction with the host.

Leaf-inhabiting endophytes-which are part of the mycobiome of a tree-demonstrate various types of trophic associations with their host [41], ranging from pathotrophy to symbiotrophy (Fig. 2). Therefore, it is expected that plant-inhabiting fungal endophytes will reveal diverse new mycoviruses [34, 42]. Another source of novel mycoviruses could be the symptomatic, as well as asymptomatic, fungi associated with woody plants. Notably, research in grapevines revealed 39 viral genomes, of which 38 had not been previously reported [43]. Mycoviral studies are especially relevant when the endophyte hosting the virus confers a plant with protection against herbivorous insects [44]. 


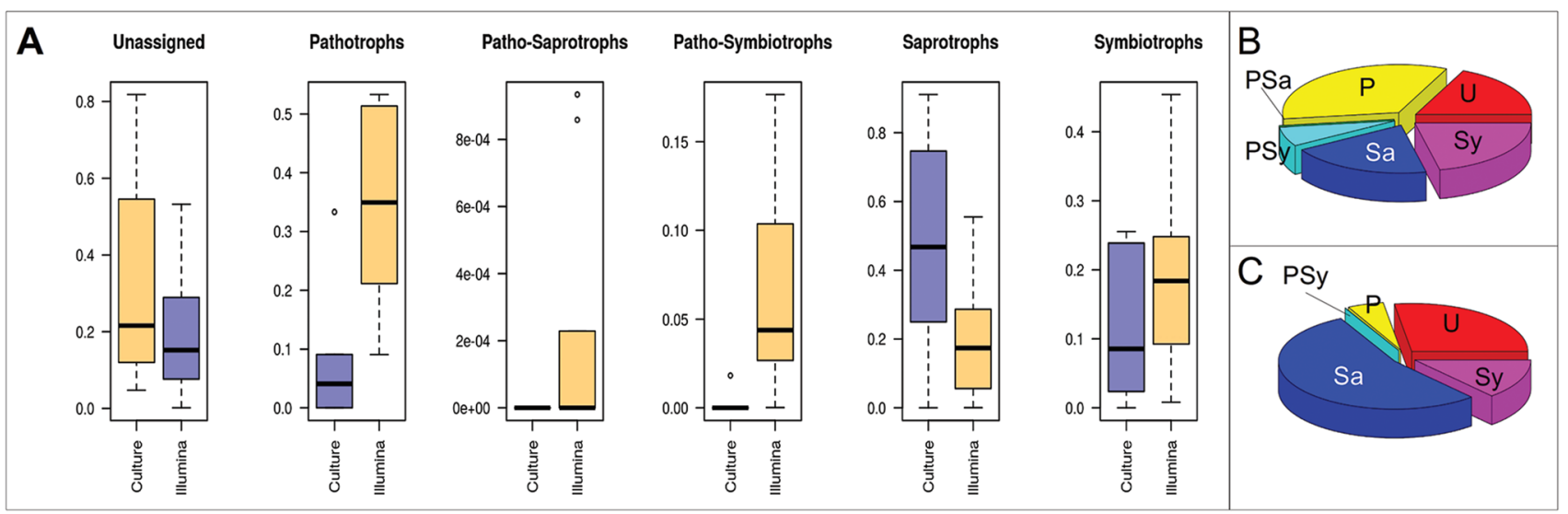

Fig. 2 Relative abundance of leaf-inhabiting fungal endophytes of European beech trees among the five main trophic guilds or associations. a compares the two methods (Illumina vs cultivation) for each trophic guild and unassigned data. $\mathbf{b}$ displays the trophic guilds and

\section{Plant-fungi-virus-environment}

Plants, fungal endophytes, mycoviruses, and the environment all participate in a four-way interactive system. In natural environments-which are constantly in flux due to various biotic and abiotic factors - these interactions are constantly shifting; for example, abiotic stress such as a drought can favor one of the components, such as the pathogen, and facilitate the infection of the host plant. Moreover, a change in any component of the interactive system may influence the whole system. As a result, a symbiotic effect may disappear while a new relationship arises [45]. It has been speculated that a symbiotic virus can make the host endophyte more, or less, pathogenic through alterations in the phenotype or gene expression profile of the infected endophyte [46]. Previous research has also suggested that these alterations may be heritable, as mycoviruses have been shown to suppress the RNA silencing defense mechanisms of the host, possibly through epigenetic changes [47].

Plants rely on symbiotic relationships with microbes to improve the nutritional condition and manage biotic and/ or abiotic stress. Both mutualism and antagonism between plants and endophytes have been extensively studied. Based on environmental conditions, this relationship may continuously shift [48]. Mycoviruses can influence the plant-endophyte relationship by either increasing or reducing host virulence (hyper- and hypovirulence, respectively) or host fitness under altered environmental conditions [32]. On the other hand, as most endophytes do not cause visible symptoms in plants, the mycovirus that exists within a certain endophyte may have a negligible influence on either the endophyte host or the plant which the endophyte is associated with. Nevertheless, several studies have shown that changes in certain unassigned taxa for Illumina data, $\mathbf{c}$ for cultivation data. b and $\mathbf{c} U$ unassigned, $P$ pathotrophs, $P S a$ patho-saprotrophs, $P S y$ patho-symbiotrophs, $S a$ saprotrophs, $S y$ symbiotrophs, adapted from Siddique et al. [41]

fungal traits, e.g., growth of mycelia, sporulation rates, or heat tolerance, following viral infection can lead to either a devastating infestation of the plant or a significantly less harmful fungal infection [34, 49, 50].

\section{Biological and ecological effects of mycoviruses in endophytic fungi and forest pathogens}

Mycoviral infections of fungi exert diverse biological and ecological effects [36]. As previously mentioned, some mycoviruses reduce the virulence of the host fungus (hypovirulence), which can make the fungus less harmful to plants, whereas other mycoviruses have been shown to enhance the virulence of the host fungus (hypervirulence). In this way, depending on the mode of action, mycoviruses could be exploited as potential bioagents to control fungal diseases. This is plausible because mycoviral infections in several fungi have been shown to cause hypovirulence. A well-known example is the use of Cryphonectria hypovirus 1 (CHV1) mycovirus, which reduces the pathogenicity of the fungus Cryphonectria parasitica, to curb chestnut blight in America [51]. Some additional examples of mycoviruses which cause hypovirulence in the host fungus are Cryphonectria hypovirus 2 (CHV2) in Cryphonectria parasitica [52], Sclerotinia sclerotiorum hypovirus 1 in Sclerotinia sclerotiorum [53], and W370dsRNA in Rosellinia necatrix [54]. Moreover, significant progress has been made in identifying and characterizing the mycoviruses and domains that cause hypovirulence in the host $[25,51$, 52]. For example, the vr1 structural domain of Fusarium graminearum virus China 9 (FgV-ch9) was found to cause 
symptoms in Fusarium graminearum [55]. In contrast, several mycoviruses cause hypervirulence following infection [56]. Furthermore, laboratory experiments demonstrated that mycoviral infection of the fungus $B$. bassiana causes a mild hypervirulent effect [57], while another research group found that the presence of viral dsRNA in Nectria radicicola increased virulence [58], along with sporulation and laccase activity. In other cases, a mycovirus can enhance certain properties of the host without conferring hypervirulence; for example, the growth rate of Monilinia fructicola increased by $10 \%$ following infection with three mycoviruses (relative to non-infected cultures) [59]. Moreover, the mold fungus Sclerotinia sclerotiorum and white root rot fungus Rosellinia necatrix were shown to host many types of mycoviruses that conferred either hypo- or hypervirulence [53, 54, 60-63]. Following mycoviral infection in Alternaria alternata, the fungus produced host-specific toxins and caused black spot in Japanese pear [64], while the infection of Aspergillus fumigatus by Aspergillus fumigatus tetramycovirus-1 (AfuTmV-1) decreased the survival rate of Galleria mellonella larvae [65]. Furthermore, initial evidence suggests that infection by Pseudogymnoascus destructans partitivirus-pa may enhance pigmentation and conidiation in the host fungus, which is responsible for widespread fatality among Northern American bats by causing white-nose syndrome [66].

Virus-fungus interactions can be beneficial, neutral, or harmful for the host [67]. Mycovirus often affect fungal morphology, spore production, growth, virulence, heat tolerance, and toxin production. Perhaps the best known example of virus-fungus interactions is Cryphonectria hypovirus 1 (CHV1)-mediated hypovirulence in Cryphonectria parasitica, the fungus which produces lethal cankers on chestnut trees $[59,68]$. Moreover, increased virulence and toxin production, as well as irregular growth, were observed in Alternaria alternata following mycoviral infection. There is currently no definitive proof about whether fungus-virus interactions help plant hosts survive in extreme environments, with most previous studies focusing on whether endophytes - both infected and non-infected-can confer heat tolerance to plant hosts [33, 69]. For example, the fungus Curvularia protuberia, when infected by a mycovirus, helped panic grass (Dichanthelium lanuginosum) tolerate excessive heat, and researchers intend to investigate whether this strategy can be extended to tomato plants [70]. Viruses have been shown to alter the transcriptome, small RNAome, proteome, metabolome, lipidome, and epigenome of the host. Transfection protocols allow researchers to study both the host range of a virus and examine host-virus interactions. In this protocol a virus nucleic acid is induced in the same host (genetically same background) and host symptom and defense responses are monitored [52, 71]. This interaction could be commercially relevant, as fungi infected by certain mycoviruses may produce secondary metabolites that have potent antimicrobial properties [42]. Hence, a bioreactor system could be developed to extract significant quantities of these antimicrobial compounds from cultured fungal cells.

\section{Influence on toxin production}

Mycoviruses have been found to affect fungal production of mycotoxins, with this effect notable at high temperatures. For example, mycovirus-infected grass fungus Tolypocladium cylindrosporum produced less fumonisin B (FB) than the virus-free strain [72], whereas mycovirus-infected Aspergillus clavatus isolates produced less patulin than control fungi [73]. Moreover, mycoviral infection in Fusarium graminearum has been associated with decreased deoxynivalenol production [74]. In wine yeasts, the synthesis of an allelopathic toxin that inhibits the growth of other fungi increases noticeably upon viral infection [75]. Nevertheless, the mechanisms through which viral infection modifies toxin production remain unclear, and warrant further research.

\section{Metagenomic studies of fungal endophytes and their mycoviruses}

Many different approaches have been used to study the biodiversity of mycoviruses, including enrichment of virus-like particles, extraction of dsRNA, and the HTS of small RNA and total RNA [43, 76, 77]. HTS methods facilitate the rapid discovery of novel viruses by simultaneously generating millions of sequences/reads from hundreds of environmental samples. Furthermore, HTS has the capability to provide high-resolution genomic and community structure data that is crucial for testing new hypotheses [78]. Currently, the most commonly used HTS platforms are Roche 454, IonTorrent, Illumina, PacBio, SOliD and NANOPORE. All of these platforms have distinct drawbacks and benefits based on the type of research they are used for; however, a detailed look into when each specific system should be applied is beyond the scope of this review. It should be stated that older technologies are currently being replaced by superior solutions; for example, most researchers agree that Roche 454 sequencing will soon be antiquated as the Illumina and PacBio systems provide lower error rates at lower prices.

The cultivation-independent analysis of myco- and microbiome communities is commonly referred to as meta'omics, which comprises metagenomic, transcriptomic, proteomic and metabolomic, aspects [11]. Due to the universality of HTS techniques, metagenomic studies have become commonplace in virome research. Current meta'omics studies in the field of virology not only focus on the simultaneous detection, identification, and characterization of novel viruses [79], but are also being performed to gain insight 
into fungal antiviral defense mechanisms, which may have applications for the biological control of pathogenic fungi.

Advanced mycovirus studies are now focused on providing data on the host transcriptome and RNA signaling [31, $68,80]$. HTS has been successfully used to detect known and unknown viruses from fungal samples [81] as well as detect mycovirus genome segments through small RNA deep sequencing [25, 82]. In addition, host transcriptome and small RNA profiling data have provided insight into the molecular mechanisms underpinning the observed changes in phenotype $[83,84]$. Genetic engineering research has started to concentrate on mycovirus-mediated hypo- or hypervirulence $[84,85]$ due to the clear link between antiviral RNA silencing and mycoviral infection [86]. The fungal antiviral defense is related to small RNA processing. By looking at sRNA accumulation and mRNA signaling, scientists have outlined genetic changes in fungi following mycoviral infection [84], although some research has not found any changes in the levels of mRNA related to genesilencing proteins following infection [84].

Meta-transcriptomic approaches can also be useful for virus identification [76, 78, 79]. Notably, Gilbert et al. [78] screened transcriptomic data for fungi from the subphylum Pezizomycotina, and found 59 viruses from 44 different fungi based on RNA-seq analyses. As such, environmental sequencing data may prove to be a valuable resource for mycovirus researchers. New mycoviruses could be discovered by analyzing old transcriptomic data which have not been used in virus research before. Furthermore, RNA sequence data in public databases could prove to be an untapped resource for virus discovery [87]. However, researchers should not solely focus on analyzing RNA sequence data, as mycoviruses with a DNA genome have also been discovered. The first instance, a geminivirusrelated ssDNA mycovirus which infects, and confers hypovirulence to, Sclerotinia sclerotiorum, was reported by $\mathrm{Yu}$ et al. [60]. Moreover, cassava associated circular single strand DNA virus was characterized from fungi that target cassava plants [88]. In a rather unique finding, a mycovirus with a DNA genome which was first isolated from a fungal pathogen was found to also infect a mycophagous insect, Lycoriella ingenua [89].

\section{Horizontal gene transfer has revealed foreign structural domains in mycoviruses}

During the process of evolution, viruses acquired genetic information from their distant hosts, whether prokaryotes, eukaryotes, plant or animals, by a mechanism known as horizontal gene transfer (HGT). For example, the homologous 'glycosyltransferase 28' domain of the Endornavirus genus [90] and the 'S7' domain of the Phytoreovirus genus are widely distributed among plants, bacteria, and fungi [91]. Furthermore, a 'SMC' (structural maintenance of chromosomes) domain was discovered in Sodiomyces alkalinus fusarivirus 1 (SaFV1). The SMC domain of SaFV1 are phylogenetically related to the SMC domains of Fusariviridae viruses, and distantly related to proteins found in bacterial and eukaryotic organisms [29]. Comparative sequence analyses of unknown viral domains could provide insight into the evolution of mycoviruses, while the role of SMC domains on the infection of fungi-which could be studied through gene expression analyses-could clarify the function of this protein in the virus life cycle. Simpler analyses can be performed by inoculating fungi with mycoviruses which include the SMC domain and following survival rates and/or phenotypic changes. Researchers can determine the function of domains which are postulated to have been acquired via HGT by expressing the protein in fungal cultures and testing whether it has a negative or positive effect on the culture. Overlap extension PCR is a simple and popular technique for cloning a viral domain into a plasmid vector without the need for restrictive endonucleases [92]. Briefly, the prepared plasmid is cloned into E. coli, and after protoplast transformation the effects of the studied protein can be monitored through either growth rate, sporulation, or gene expression via qPCR [55, 93]. Phylogenetic analyses can then be used to explore the evolutionary origins of structural and potential HGT-acquired domains present in mycoviruses. Streamlined protocols for horizontal gene transfer, foreign structural domain, and phylogenetic relationship analyses currently exist for mycoviruses (refer to [90, 91]).

Virus metagenomic research has revealed that RNA viruses which infect fungi, plants, and vertebrates evolved by multiple instances of horizontal virus transfer. The analysis of RNA-dependent RNA polymerases (RdRp) and small RNA present in viruses strongly support that various groups of viruses have diverse hosts, including protists, fungi, plants, and animals [94].

Some plant viruses seem to infect fungi and replicate in fungal cells [94-96]. For example, experiments in which fungal spheroplasts were transfected with hop stunt (HSVd), iresine 1 , and avocado sunblotch viriods revealed that the tested viruses were able to replicate in at least one of the studied fungi (e.g., Cryphonectria parasitica, Valsa mali, and Fusarium graminearum) [97]. Furthermore, horizontal transmission of cucumber mosaic virus (CMV) was observed in the phytopathogenic fungus Rhizoctonia solani [98]. Far less is known about the mycoviruses that infect, and replicate in, plant cells $[99,100]$. Notably, the fungal virus CHV1 was only able to systemically infect Nicotiana tabacaum plants when inoculated together with other plant viruses or tobacco mosaic virus (TMV), which indicates facilitative interactions between fungi and plant viruses [101]. Mitoviral sequences have been identified in both fungi 
and plants, with researchers speculating that ancestral mitoviruses became endosymbionts and, for this reason, partial copies of mitovirus RdRP can be detected in plant nuclear and mitochondrial genomes [67, 102]. Furthermore, protein sequence analyses provide evidence that members of the mycovirus family Hypoviridae may be related to plantinfecting Potyviruses [103].

\section{Biological control strategies for forest pathogens}

In the near future, we may see many cases in which biological control-via hypovirulence of pathogenic fungi-is used to curb woody plant diseases. Using mycoviruses to combat woody plant diseases caused by pathogenic fungi is an important research topic because this measure could significantly decrease the use of chemical control, which has adverse environmental impacts. It should be noted that there are already precedents for this type of control strategy, as CHV1 was applied to Cryphonectria parasitica in order to combat chestnut blight in America. Martín-García et al. [104] outlined four effective strategies for using mycoviruses to control pathogenic fungi:

i Identify viruses that cause hypovirulence

ii Check if the virus can infect most fungal strains

iii Determine a cost-effective method for disseminating the virus into host populations

iv Test if the virus is persistent in most strains under natural conditions

\section{Conclusions and future perspectives}

This review has presented various viruses of fungal endophytes and forest pathogens and is relevant in the context of fungal research because it has been estimated that up to $80 \%$ of fungi are infected by mycoviruses, resulting in positive, negative, or negligible effects in the host. Moreover, the review has covered the biodiversity of mycoviruses, the four-way interactive system including viruses, fungi, plants, and the environment, how mycoviral infection can influence symbiotic relationships, infection-mediated hypoand hypervirulence, antimicrobial properties, the evolution of viruses through horizontal gene transfer, and the role of mycoviruses disease control strategies.

Impending climate change may support the spread of forest pathogens and diseases and play a role in widespread forest epidemics. Based on significant changes in the environment, alterations in the relationship between endophytic fungi and plants may underlie future outbreaks of fungal infection and disease. This can be expected to increase the chemical control of disease spread, which is worrying as chemical compounds are already excessively used in the fields and forests of many countries, with a clear negative effect on friendly biota [105, 106]. Environment-friendly management, also referred to as biological control or biocontrol, has been touted as a way to eradicate the use chemical fungicides. This review presents various lines of evidence for why researchers should further study the mycoviruses of endophytic fungi to build the knowledge base of virusendophyte interactions. As our understanding of the viruses of fungal endophytes and forest pathogens is only at the very beginning, it is an ideal time to develop sequenced-based tools for the detection and identification of further mycoviruses. The decreased costs of metagenomics approaches and amount of available bioinformatic approaches mean that researchers can investigate virus genomes in both temporal and spatial scales. Furthermore, the combination of HTS and environment- or biome-wide data could enable researchers to explore mycoviral domains/structures within different endophytes to make evolutionary inferences. Until now, only mycoviruses of widespread pathogenic fungi have been characterized, but this review provides evidence that a diverse set of mycoviruses remain to be discovered from either forest samples or publicly available DNA or RNA sequence repositories.

Acknowledgements Open access funding provided by Umea University. I would like to thank Prof. RNDr. Karel Petrzik and Dr. Igor Koloniuk from the plant virology department (The Institute of Plant Molecular Biology (IPMB), Biology Centre CAS, Ceske Budejovice, Czech Republic) for their feedback and helpful suggestions.

\section{Compliance with ethical standards}

Conflict of interest The authors declare that they have no conflict of interests.

Ethical approval This article does not contain any experiments involving human participants or animals.

Open Access This article is licensed under a Creative Commons Attribution 4.0 International License, which permits use, sharing, adaptation, distribution and reproduction in any medium or format, as long as you give appropriate credit to the original author(s) and the source, provide a link to the Creative Commons licence, and indicate if changes were made. The images or other third party material in this article are included in the article's Creative Commons licence, unless indicated otherwise in a credit line to the material. If material is not included in the article's Creative Commons licence and your intended use is not permitted by statutory regulation or exceeds the permitted use, you will need to obtain permission directly from the copyright holder. To view a copy of this licence, visit http://creativecommons.org/licenses/by/4.0/. 


\section{References}

1. Petrini O (1991) Fungal endophytes of tree leaves. In: Andrews JH, Hirano SS (eds) Microbial ecology of leaves. Springer, New York, pp 179-197

2. Schulz B, Boyle C (2005) The endophytic continuum. Mycol Res 109:661-686. https://doi.org/10.1017/S095375620500273X

3. U'Ren JM, Lutzoni F, Miadlikowska J, Arnold AE (2010) Community analysis reveals close affinities between endophytic and endolichenic fungi in mosses and lichens. Microb Ecol 60:340353. https://doi.org/10.1007/s00248-010-9698-2

4. Richards TA, Jones MD, Leonard G, Bass D (2012) Marine fungi: their ecology and molecular diversity. Annu Rev Mar Sci 4:495. https://doi.org/10.1146/annurev-marine-120710-100802

5. Tedersoo L, Bahram M, Põlme S et al (2014) Global diversity and geography of soil fungi. Science 346:1256688. https://doi. org/10.1126/science. 1256688

6. Dighton J (2016) Fungi in ecosystem processes. CRC Press, Boca Raton

7. Peay KG, Kennedy PG, Talbot JM (2016) Dimensions of biodiversity in the Earth mycobiome. Nat Rev Microbiol 14:434-447

8. Smith SE, Read DJ (2010) Mycorrhizal symbiosis. Academic Press, Boston

9. Baldrian P (2017) Forest microbiome: diversity, complexity and dynamics. FEMS Microbiol Rev 41:109-130. https://doi. org/10.1093/femsre/fuw040

10. Voříšková J, Baldrian P (2013) Fungal community on decomposing leaf litter undergoes rapid successional changes. ISME J 7:477-486. https://doi.org/10.1038/ismej.2012.116

11. Peršoh D (2015) Plant-associated fungal communities in the light of meta'omics. Fungal Divers 75:1-25. https://doi. org/10.1007/s13225-015-0334-9

12. Schardl CL, Leuchtmann A, Spiering MJ (2004) Symbioses of grasses with seedborne fungal endophytes. Annu Rev Plant Biol 55:315

13. Suryanarayanan TS (2013) Endophyte research: going beyond isolation and metabolite documentation. Fungal Ecol 6:561568. https://doi.org/10.1016/j.funeco.2013.09.007

14. Davis EC, Shaw AJ (2008) Biogeographic and phylogenetic patterns in diversity of liverwort-associated endophytes. Am J Bot 95:914-924. https://doi.org/10.3732/ajb.2006463

15. Arnold AE, Herre EA (2003) Canopy cover and leaf age affect colonization by tropical fungal endophytes: ecological pattern and process in Theobroma cacao (Malvaceae). Mycologia 95:388-398

16. Ganley RJ, Sniezko RA, Newcombe G (2008) Endophytemediated resistance against white pine blister rust in Pinus monticola. For Ecol Manag 255:2751-2760. https://doi. org/10.1016/j.foreco.2008.01.052

17. Albrectsen BR, Björkén L, Varad A et al (2010) Endophytic fungi in European aspen (Populus tremula) leaves-diversity, detection, and a suggested correlation with herbivory resistance. Fungal Divers 41:17-28

18. Albrectsen BR, Siddique AB, Decker VHG et al (2018) Both plant genotype and herbivory shape aspen endophyte communities. Oecologia 187:535-545. https://doi.org/10.1007/s0044 2-018-4097-3

19. Pearson MN, Beever RE, Boine B, Arthur K (2009) Mycoviruses of filamentous fungi and their relevance to plant pathology. Mol Plant Pathol 10:115-128. https://doi.org/10.111 1/j.1364-3703.2008.00503.x
20. Hollings M (1962) Viruses associated with a die-back disease of cultivated mushroom. Nature 196:962. https://doi. org/10.1038/196962a0

21. Nerva L, Ciuffo M, Vallino M et al (2016) Multiple approaches for the detection and characterization of viral and plasmid symbionts from a collection of marine fungi. Virus Res 219:22-38. https://doi.org/10.1016/j.virusres.2015.10.028

22. Ghabrial SA, Suzuki N (2009) Viruses of plant pathogenic fungi. Annu Rev Phytopathol 47:353-384. https://doi. org/10.1146/annurev-phyto-080508-081932

23. Nibert ML, Ghabrial SA, Maiss E et al (2014) Taxonomic reorganization of family Partitiviridae and other recent progress in partitivirus research. Virus Res 188:128-141. https://doi. org/10.1016/j.virusres.2014.04.007

24. Sato Y, Miyazaki N, Kanematsu S et al (2019) ICTV Virus Taxonomy profile: megabirnaviridae. J Gen Virol 100:12691270. https://doi.org/10.1099/jgv.0.001297

25. Ghabrial SA, Castón JR, Jiang D et al (2015) 50-plus years of fungal viruses. Virology 479-480:356-368. https://doi. org/10.1016/j.virol.2015.02.034

26. Blackwell M (2011) The fungi: 1, 2, 3 .. 5.1 million species? Am J Bot 98:426-438. https://doi.org/10.3732/ajb.1000298

27. Bass D, Richards TA (2011) Three reasons to re-evaluate fungal diversity 'on earth and in the ocean'. Fungal Biol Rev 25:159164. https://doi.org/10.1016/j.fbr.2011.10.003

28. Neupane A, Feng C, Feng J et al (2018) Metatranscriptomic analysis and in silico approach identified mycoviruses in the arbuscular mycorrhizal fungus Rhizophagus spp. Viruses 10:707. https://doi.org/10.3390/v10120707

29. Hrabáková L, Grum-Grzhimaylo AA, Koloniuk I et al (2017) The alkalophilic fungus Sodiomyces alkalinus hosts beta- and gammapartitiviruses together with a new fusarivirus. PLoS ONE 12:e0187799. https://doi.org/10.1371/journal.pone.0187799

30. Liu C, Li M, Redda ET et al (2019) Complete nucleotide sequence of a novel mycovirus from Trichoderma harzianum in China. Arch Virol 164:1213-1216. https://doi.org/10.1007/s0070 5-019-04145-9

31. Zheng L, Zhao J, Liang X et al (2019) Complete genome sequence of a novel mitovirus from the wheat stripe rust fungus Puccinia striiformis. Arch Virol 164:897-901. https://doi. org/10.1007/s00705-018-04134-4

32. Bao X, Roossinck MJ (2013) Chapter two-multiplexed interactions: viruses of endophytic fungi. In: Ghabrial SA (ed) Advances in virus research. Academic Press, Boston, pp 37-58

33. Herrero N, Sánchez Márquez S, Zabalgogeazcoa I (2009) Mycoviruses are common among different species of endophytic fungi of grasses. Arch Virol 154:327-330. https://doi.org/10.1007/ s00705-008-0293-5

34. Herrero N, Zabalgogeazcoa I (2011) Mycoviruses infecting the endophytic and entomopathogenic fungus Tolypocladium cylindrosporum. Virus Res 160:409-413. https://doi.org/10.1016/j. virusres.2011.06.015

35. Figueirêdo LC, Figueirêdo GS, Giancoli ÁCH et al (2012) Detection of isometric, dsRNA-containing viral particles in Colletotrichum gloeosporioides isolated from cashew tree. Trop Plant Pathol 37:142-145. https://doi.org/10.1590/S1982-5676201200 0200007

36. Ong JWL, Li H, Sivasithamparam K et al (2016) Novel Endornalike viruses, including three with two open reading frames, challenge the membership criteria and taxonomy of the Endornaviridae. Virology 499:203-211. https://doi.org/10.1016/j.virol .2016.08.019 
37. Ong JWL, Li H, Sivasithamparam K et al (2018) Novel and divergent viruses associated with Australian orchid-fungus symbioses. Virus Res 244:276-283. https://doi.org/10.1016/j.virus res.2017.11.026

38. Song HY, Choi HJ, Jeong H et al (2016) Viral effects of a dsRNA mycovirus (PoV-ASI2792) on the vegetative growth of the edible mushroom Pleurotus ostreatus. Mycobiology 44:283-290. https ://doi.org/10.5941/MYCO.2016.44.4.283

39. Lin YH, Fujita M, Chiba S et al (2019) Two novel fungal negative-strand RNA viruses related to mymonaviruses and phenuiviruses in the shiitake mushroom (Lentinula edodes). Virology 533:125-136. https://doi.org/10.1016/j.virol.2019.05.008

40. Petrzik K, Siddique AB (2019) A mycoparasitic and opportunistic fungus is inhabited by a mycovirus. Arch Virol 164:25452549. https://doi.org/10.1007/s00705-019-04359-x

41. Siddique AB, Khokon AM, Unterseher M (2017) What do we learn from cultures in the omics age? High-throughput sequencing and cultivation of leaf-inhabiting endophytes from beech (Fagus sylvatica L.) revealed complementary community composition but similar correlations with local habitat conditions. MycoKeys 20:1-16. https://doi.org/10.3897/mycokeys.20.11265

42. Rosseto P, Costa AT, Polonio JC et al (2016) Investigation of mycoviruses in endophytic and phytopathogenic strains of colletotrichum from different hosts. Genet Mol Res. https://doi. org/10.4238/gmr. 15017651

43. Nerva L, Turina M, Zanzotto A et al (2019) Isolation, molecular characterization and virome analysis of culturable wood fungal endophytes in esca symptomatic and asymptomatic grapevine plants. Environ Microbiol. https://doi. org/10.1111/1462-2920.14651

44. Muvea AM, Subramanian S, Maniania NK et al (2018) Endophytic colonization of onions induces resistance against Viruliferous thrips and virus replication. Front Plant Sci 9:1785. https:// doi.org/10.3389/fpls.2018.01785

45. Morsy MR, Oswald J, He J et al (2010) Teasing apart a threeway symbiosis: transcriptome analyses of Curvularia protuberata in response to viral infection and heat stress. Biochem Biophys Res Commun 401:225-230. https://doi.org/10.1016/j. bbrc.2010.09.034

46. Segers GC, Zhang X, Deng F, Sun Q, Nuss DL (2007) Evidence that RNA silencing functions as an antiviral defense mechanism in fungi. Proc Natl Acad Sci USA 104:12902-12906

47. Hammond TM, Andrewski MD, Roossinck MJ, Keller NP (2008) Aspergillus mycoviruses are targets and suppressors of RNA silencing. Eukaryot Cell 7:350-357

48. Saikkonen K, Faeth SH, Helander M, Sullivan TJ (1998) Fungal endophytes: a continuum of interactions with host plants. Annu Rev Ecol Syst 29:319-343

49. Zabalgogeazcoa I, Benito EP, Ciudad AG et al (1998) Double-stranded RNA and virus-like particles in the grass endophyte Epichloe festucae. Mycol Res 102:914-918. https://doi. org/10.1017/S0953756297005819

50. Aoki N, Moriyama H, Kodama M et al (2009) A novel mycovirus associated with four double-stranded RNAs affects host fungal growth in Alternaria alternata. Virus Res 140:179-187. https:// doi.org/10.1016/j.virusres.2008.12.003

51. Nuss DL (2005) Hypovirulence: mycoviruses at the fungal-plant interface. Nat Rev Microbiol 3:632-642. https://doi.org/10.1038/ nrmicro1206

52. Dawe AL, Nuss DL (2013) Hypovirus molecular biology. In: Maramorosch K, Murphy F (eds) Advances in virus research. Academic Press, Boston, pp 109-147
53. Xie J, Xiao X, Fu Y et al (2011) A novel mycovirus closely related to hypoviruses that infects the plant pathogenic fungus Sclerotinia sclerotiorum. Virology 418:49-56. https://doi. org/10.1016/j.virol.2011.07.008

54. Kanematsu S, Arakawa M, Oikawa Y et al (2004) A reovirus causes hypovirulence of Rosellinia necatrix. Phytopathology 94:561-568. https://doi.org/10.1094/PHYTO.2004.94.6.561

55. Bormann J, Heinze C, Blum C et al (2018) Expression of a structural protein of the mycovirus $\mathrm{FgV}$-ch9 negatively affects the transcript level of a novel symptom alleviation factor and causes virus infection-like symptoms in Fusarium graminearum. J Virol 92:e00326-e418. https://doi.org/10.1128/JVI.00326-18

56. Özkan S, Coutts RHA (2015) Aspergillus fumigatus mycovirus causes mild hypervirulent effect on pathogenicity when tested on Galleria mellonella. Fungal Genet Biol 76:20-26. https://doi. org/10.1016/j.fgb.2015.01.003

57. Kotta-Loizou I, Coutts RHA (2017) Studies on the virome of the entomopathogenic fungus Beauveria bassiana reveal novel dsrna elements and mild hypervirulence. PLoS Pathog. https:// doi.org/10.1371/journal.ppat.1006183

58. Ahn IP, Lee YH (2001) A viral double-stranded RNA up regulates the fungal virulence of Nectria radicicola. Mol Plant Microbe Interact 14:496-507. https://doi.org/10.1094/ MPMI.2001.14.4.496

59. Tran TT, Li H, Nguyen DQ et al (2019) Co-Infection with three mycoviruses stimulates growth of a Monilinia fructicola isolate on nutrient medium, but does not induce hypervirulence in a natural host. Viruses 11:89. https://doi.org/10.3390/v110100896 0

60. Yu X, Li B, Fu Y et al (2010) A geminivirus-related DNA mycovirus that confers hypovirulence to a plant pathogenic fungus. Proc Natl Acad Sci USA 107:8387-8392. https://doi. org/10.1073/pnas.0913535107

61. Jiang D, Fu Y, Guoqing L, Ghabrial SA (2013) Viruses of the plant pathogenic fungus Sclerotinia sclerotiorum. Adv Virus Res 86:215-248

62. Kondo H, Kanematsu S, Suzuki N (2013) Viruses of the white root rot fungus, Rosellinia necatrix. Adv Virus Res 86:177-214

63. Xie J, Jiang D (2014) New insights into mycoviruses and exploration for the biological control of crop fungal diseases. Annu Rev Phytopathol 52:45-68. https://doi.org/10.1146/annurev-phyto $-102313-050222$

64. Fuke K, Takeshita K, Aoki N et al (2011) The presence of double-stranded RNAs in Alternaria alternata Japanese pear pathotype is associated with morphological changes. J Gen Plant Pathol 77:248-252. https://doi.org/10.1007/s10327-011-0315-0

65. Kanhayuwa L, Kotta-Loizou I, Özkan S et al (2015) A novel mycovirus from Aspergillus fumigatus contains four unique dsRNAs as its genome and is infectious as dsRNA. Proc Natl Acad Sci USA 112:9100-9105. https://doi.org/10.1073/pnas.14192 25112

66. Thapa V, Turner GG, Hafenstein S et al (2016) Using a novel partitivirus in Pseudogymnoascus destructans to understand the epidemiology of white-nose syndrome. PLoS Pathog. https://doi. org/10.1371/journal.ppat.1006076

67. Hillman BI, Annisa A, Suzuki N (2018) Chapter five-viruses of plant-interacting fungi. In: Kielian M, Mettenleiter TC, Roossinck MJ (eds) Advances in virus research. Academic Press, Boston, pp 99-116

68. Zhanga D-X, Nussa DL (2016) Engineering super mycovirus donor strains of chestnut blight fungus by systematic disruption of multilocus vic genes. Proc Natl Acad Sci USA 113:20622067. https://doi.org/10.1073/pnas.1522219113 
69. Márquez LM, Redman RS, Rodriguez RJ, Roossinck MJ (2007) A virus in a fungus in a plant: three-way symbiosis required for thermal tolerance. Science 315:513-515. https://doi.org/10.1126/ science. 1136237

70. Herrero Asensio N, Sánchez Márquez S, Zabalgogeazcoa I (2013) Mycovirus effect on the endophytic establishment of the entomopathogenic fungus Tolypocladium cylindrosporum in tomato and bean plants. Biocontrol 58:225-232. https://doi. org/10.1007/s10526-012-9476-9

71. Suzuki N (2017) Frontiers in fungal virology. J Gen Plant Pathol 83:419-423. https://doi.org/10.1007/s10327-017-0740-9

72. Zabalgogeazcoa I, Alvarez A, Herrero N, Vazquez-de-Aldana BR (2018) Production of fumonisins by endophytic strains of Tolypocladium cylindrosporum and its relation to fungal virus infection. Mycotoxin Res 34:49-57. https://doi.org/10.1007/ s12550-017-0298-6

73. Varga J, Rigó K, Molnár J et al (2003) Mycotoxin production and evolutionary relationships among species of Aspergillus section Clavati. Antonie Van Leeuwenhoek 83:191-200. https://doi. org/10.1023/A:1023355707646

74. Chu YM, Jeon JJ, Yea SJ et al (2002) Double-stranded RNA mycovirus from Fusarium graminearum. Appl Environ Microbiol 68:2529-2534. https://doi.org/10.1128/ AEM.68.5.2529-2534.2002

75. Rodríguez-Cousiño N, Gómez P, Esteban R (2013) LA-lus, a new variant of the LA totivirus found in wine yeasts with Klus killer toxin-encoding Mlus double-stranded RNA: possible role of killer toxin-encoding satellite RNAs in the evolution of their helper viruses. Appl Environ Microbiol 79:4661-4674. https:// doi.org/10.1128/AEM.00500-13

76. Marzano SYL, Domier LL (2016) Reprint of "Novel mycoviruses discovered from metatranscriptomics survey of soybean phyllosphere phytobiomes". Virus Res 219:11-21. https://doi. org/10.1016/j.virusres.2016.05.012

77. Nerva L, Varese GC, Turina M (2018) Different approaches to discover mycovirus associated to marine organisms. Methods Mol Biol 1746:97-114. https://doi.org/10.1007/978-1-4939-7683-6_8

78. Gilbert K, Holcomb EE, Allscheid RL, Carrington JC (2019) Hiding in plain sight: New virus genomes discovered via a systematic analysis of fungal public transcriptomes. PLoS ONE 14:e0219207. https://doi.org/10.1371/journal.pone.0219207

79. Marzano SYL, Nelson BD, Ajayi-Oyetunde O et al (2016) Identification of diverse mycoviruses through metatranscriptomics characterization of the viromes of five major fungal plant pathogens. J Virol 90:6846-6863. https://doi.org/10.1128/JVI.00357 $-16$

80. Nibert ML, Debat HJ, Manny AR et al (2019) Mitovirus and mitochondrial coding sequences from basal fungus Entomophthora muscae. Viruses. https://doi.org/10.3390/v11040351

81. Pandey B, Naidu RA, Grove GG (2018) Next generation sequencing analysis of double-stranded RNAs from sweet cherry powdery mildew fungus Podosphaera prunicola. J Plant Pathol 100:435-446. https://doi.org/10.1007/s42161-018-0092-0

82. Vainio EJ, Jurvansuu J, Streng J et al (2015) Diagnosis and discovery of fungal viruses using deep sequencing of small RNAs. J Gen Virol 96:714-725. https://doi.org/10.1099/jgv.0.000003

83. Ejmal MA, Holland DJ, Macdiarmid RM, Pearson MN (2018) The effect of Aspergillus thermomutatus chrysovirus 1 on the biology of three Aspergillus species. Viruses 10:1-21. https:// doi.org/10.3390/v10100539

84. Lee Marzano SY, Neupane A, Domier L (2018) Transcriptional and small RNA responses of the white mold fungus Sclerotinia sclerotiorum to infection by a virulence-attenuating hypovirus. Viruses 10:713. https://doi.org/10.3390/v10120713
85. Mochama P, Jadhav P, Neupane A, Marzano SYL (2018) Mycoviruses as triggers and targets of RNA silencing in white mold fungus Sclerotinia sclerotiorum. Viruses. https://doi.org/10.3390/ v10040214

86. Kotta-Loizou I (2019) Mycoviruses: past, present, and future. Viruses 11:361. https://doi.org/10.3390/v1104036187

87. Mokili JL, Rohwer F, Dutilh BE (2012) Metagenomics and future perspectives in virus discovery. Curr Opin Virol 2:63-77. https ://doi.org/10.1016/j.coviro.2011.12.004

88. Dayaram A, Opong A, Jäschke A et al (2012) Molecular characterisation of a novel cassava associated circular ssDNA virus. Virus Res 166:130-135. https://doi.org/10.1016/j.virus res.2012.03.009

89. Liu S, Xie J, Cheng J et al (2016) Fungal DNA virus infects a mycophagous insect and utilizes it as a transmission vector. Proc Natl Acad Sci USA 113:12803-12808. https://doi.org/10.1073/ pnas. 1608013113

90. Song D, Cho WK, Park SH et al (2013) Evolution of and horizontal gene transfer in the Endornavirus genus. PLoS ONE 8:e64270. https://doi.org/10.1371/journal.pone.0064270

91. Liu H, Fu Y, Xie J et al (2012) Evolutionary genomics of mycovirus-related dsRNA viruses reveals cross-family horizontal gene transfer and evolution of diverse viral lineages. BMC Evol Biol 12:91. https://doi.org/10.1186/1471-2148-12-91

92. Bryksin AV, Matsumura I (2010) Overlap extension PCR cloning: a simple and reliable way to create recombinant plasmids. Biotechniques 48:463-465. https://doi.org/10.2144/000113418

93. Li P, Zhang H, Chen X et al (2015) Molecular characterization of a novel hypovirus from the plant pathogenic fungus Fusarium graminearum. Virology 481:151-160. https://doi.org/10.1016/j. virol.2015.02.047

94. Dolja VV, Koonin EV (2018) Metagenomics reshapes the concepts of RNA virus evolution by revealing extensive horizontal virus transfer. Virus Res 244:36-52. https://doi.org/10.1016/j. virusres.2017.10.020

95. Donaire L, Rozas J, Ayllón MA (2016) Molecular characterization of Botrytis ourmia-like virus, a mycovirus close to the plant pathogenic genus Ourmiavirus. Virology 489:158-164. https:// doi.org/10.1016/j.virol.2015.11.027

96. Roossinck MJ (2019) Evolutionary and ecological links between plant and fungal viruses. New Phytol 221:86-92. https://doi. org/10.1111/nph.15364

97. Wei S, Bian R, Andika IB, Niu E et al (2019) Symptomatic plant viroid infections in phytopathogenic fungi. Proc Natl Acad Sci USA 116:13042-13050. https://doi.org/10.1073/pnas.19007 62116

98. Andika IB, Wei S, Cao C, Salaipeth L, Kondo H, Sun L (2017) Phytopathogenic fungus hosts a plant virus: a naturally occurring cross-kingdom viral infection. Proc Natl Acad Sci USA 114:12267-12272. https://doi.org/10.1073/pnas.1714916114

99. Nerva L, Varese GC, Falk BW, Turina M (2017) Mycoviruses of an endophytic fungus can replicate in plant cells: evolutionary implications. Sci Rep 7:1-11. https://doi.org/10.1038/s4159 8-017-02017-3

100. Mascia T, Vučurović A, Minutillo SA et al (2018) Infection of Colletotrichum acutatum and Phytophthora infestans by taxonomically different plant viruses. Eur J Plant Pathol 153:10011017. https://doi.org/10.1007/s10658-018-01615-9

101. Bian R, Andika IB, Pang T et al (2020) Facilitative and synergistic interactions between fungal and plant viruses. Proc Natl Acad Sci USA 117:3779-3788. https://doi.org/10.1073/pnas.19159 96117 
102. Bruenn JA, Warner BE, Yerramsetty P (2015) Widespread mitovirus sequences in plant genomes. PeerJ. https://doi.org/10.7717/ peerj. 876

103. Koonin EV, Choi GH, Nuss DL et al (1991) Evidence for common ancestry of a chestnut blight hypovirulence-associated double-stranded RNA and a group of positive-strand RNA plant viruses. Proc Natl Acad Sci USA 88:10647-10651. https://doi. org/10.1073/pnas.88.23.10647

104. Martín-García J, Zas R, Solla A et al (2019) Environmentally friendly methods for controlling pine pitch canker. Plant Pathol 68:843-860. https://doi.org/10.1111/ppa.13009
105. Carvalho FP (2017) Pesticides, environment, and food safety. Food and Energy Sec 6:48-60. https://doi.org/10.1002/fes3.108

106. WHO (2017) Agrochemicals, health and environment: directory of resources. HELI publishing. https://www.who.int/heli/risks/ toxics/chemicalsdirectory/en/index 1.html. Accessed 24 March 2020

Publisher's Note Springer Nature remains neutral with regard to jurisdictional claims in published maps and institutional affiliations. 